\title{
INFLUENCE OF FLEXURAL STRENGTH ON WELDED JOINTS UNDER THE EFFECT OF ELECTRODE VIBRATORY WELDING PROCESS
}

\section{BADE VENKATA SURESH ${ }^{1}$, P. SRINIVASA RAO ${ }^{2 *} \&$ POTNURU GOVINDA RAO ${ }^{3}$}

${ }^{1}$ Ph.D Scholar, Department of Mechanical Engineering Centurion University of Technology and Management, Odisha, India

${ }^{1}$ Department of Mechanical Engineering, GMR Institute of Technology, Rajam, Andhra Pradesh, India

${ }^{2}$ Department of Mechanical Engineering, Centurion University of Technology and Management, Odisha, India

${ }^{3}$ Department. of Mechanical Engineering, Avanthi's Research \& Technological Academy, Andhra Pradesh, India

\begin{abstract}
Vibration techniques play a prominent role in welding process for enhancing the mechanical properties of material from past two decades. In this current work, electrode vibratory setup is connected to the electrode for transferring vibrations mechanically through electrode to weld-pool during arc welding process. The fabricated novel vibratory setup generates the required amount of frequency in-terms DC motor voltage. Through these vibrations an enhanced flexural strength of weldments at HAZ is studied. The improved mechanical properties are due to refinement of the weld-pool before solidification and the dendrites are breaks down into smaller size. The microstructure analysis reveals the small nuclei formation which is the main reason for improved flexural strength.
\end{abstract}

KEYWORDS: Flexural Strength, Vibrations, Fine Grains \& Frequency

Received: Jun 01, 2020; Accepted: Jun 20, 2020; Published: Jun 29, 2020; Paper Id.: IJMPERDJUN2020117

\section{INTRODUCTION}

Welding is a permanent mating technique in which metal or non-metals can be joined together with or without application of heat, pressure and filler material. Welding a joint can be performed with lesser effort than the bolted or riveted joint. Welding parameters in welding decides quality of the weld and the life span of that weld joint. The parameters like welding current, electrode size, arc length, welding current, welding voltage and weld travel speed have lot of effect on weld bead quality. Shigeru Aoki[1] finds a new method to reduce residual stress of welded joint. Post welding thermal treatment for diminishing stresses harmonic vibration load is applied. In this experimentation welding $\mathrm{CO}_{2}$ gas is used as shielded arc during welding process. After consummation of vibration welding process at various it is identified that the stresses for single side welding For natural and harmonic were used and identified there is a reduced levels of residual stress. The similar phenomena are continued for both side of the specimen during welding and obtained the same improved results. J. Kalpana[2] introduced a new technique for incorporating vibrations during welding. In this process required amount of vibrations are generated at various frequencies with respect to voltage. Here dissimilar materials are considered for welding with the application of vibrations and identified the improvement in the tensile strength. By using tig welding process the process of welding is done with vibrations After the process of welding the prepared weldments were sectioned to dimensions as per ASTM.

A.S.M.Y. Munsi, et.al [3] compared residual stress produced at the welded zone for both the specimens prepared with vibration welding and specimens undergone for heat treatment. With this it identified that vibrations during the process of welding can replace heat treatment after welding. When the life of fatigue of welded specimens 
is studied, it is minimized by $43 \%$ in heat relieved weldments and it reduced by $15 \%$ to $35 \%$ when it is done with welding with vibrations. Alaa Raad Hussein et.al[4] performed experiments by connecting the vibratory setup to reduce the internal stress stress. With this it is found that the vibrations inducement plays a prominent role in enhancing mechanical properties of the weldments, and also identified the improved level of ductility. P. Govinda Rao, and Dr. C L V R S V Prasad[5] introduced a novel approach of vibrating specimens during the process of welding. Welding is mating process in which produces more internal stress, which influences the characteristics of the joint with internal stresses because of applied loads. The internal stresses because of grain growth are compared with different properties of joint mechanically, with the application of vibrations and without the vibrations and also evaluated the crack and ultimate strength.

Tso-Liang Teng et.al.[6] predicted the development of stresses during welding is because of different weld defects. In order to minimize these weld defects vibration incorporation is done along with the multi pass process. A.J. Waddell and C.A. Walker, D.J. Jhonson[7] used vibratory stress relief (VSR) technique by cyclic loading treatments. They found that apart from increase in mechanical properties such as hardness and tensile strength, there is decrease in fatigue strength of the specimens welded with vibration assisted welding, which shows a drawback of the technique. Kuo et al.[8] studied and investigate the process of introducing vibrations to diminish the internal stress. Prepared joints transferred after welding process to the excitations. The vibrating methods to remove or reduce the weldements stress electro magnatic and mechanical beating is utilized. With that the enhanced strength of the joints is identified. Węglowska et al[9]. studied the excitations during the process welding reduces the size of the dendrites formation and improves or reduces the weld defects. Microscopic analysis is conducted to understand the causes for the improved properties of weld joint strength and hardness. The fine grain nuclei formation improves the properties of the weldment. Rao et al[10]. Experimentations are conducted with cyclic stress and strain on 304L steel weldments using system of material testing. And simulated the results of cyclic loadings during tensile loads and compressive loads is compared. The results of experimentation refelects the dynamic condition of the strain is featured as continues creep.

Zhu et al[11]. Introduced a vibratory conditioning setup which is connected to electro-slag welding for steel materials and tensile properties of prepared joint were studied. The obtained results proved the excitations technology can significantly increases the tensile properties of mated joints. specially at the $0.6 \mathrm{~mm}$ amplitude. Bade V S et.al., [12] is also studied the improved hardness of the weldments with vibrations.

\section{Electrode Vibratory Welding Equipment Setup}

For placing specimens, a table is utilized during welding. The adapter is connected which converts alternate current supply to direct current supply and voltage is converted with the help of a converter. The controller which is connected is having capacity to alter the voltage from 0V to 20V. When Direct Current is transferred to the DC motor, it rotates and as it is connected mechanically to the electrode, the electrode vibrates and The motor vibrations transferred to the electrode which is in direct contact to the electrode, with this the electrode starts vibrating. The line diagram of the electrode vibration welding is shown in figure1. 


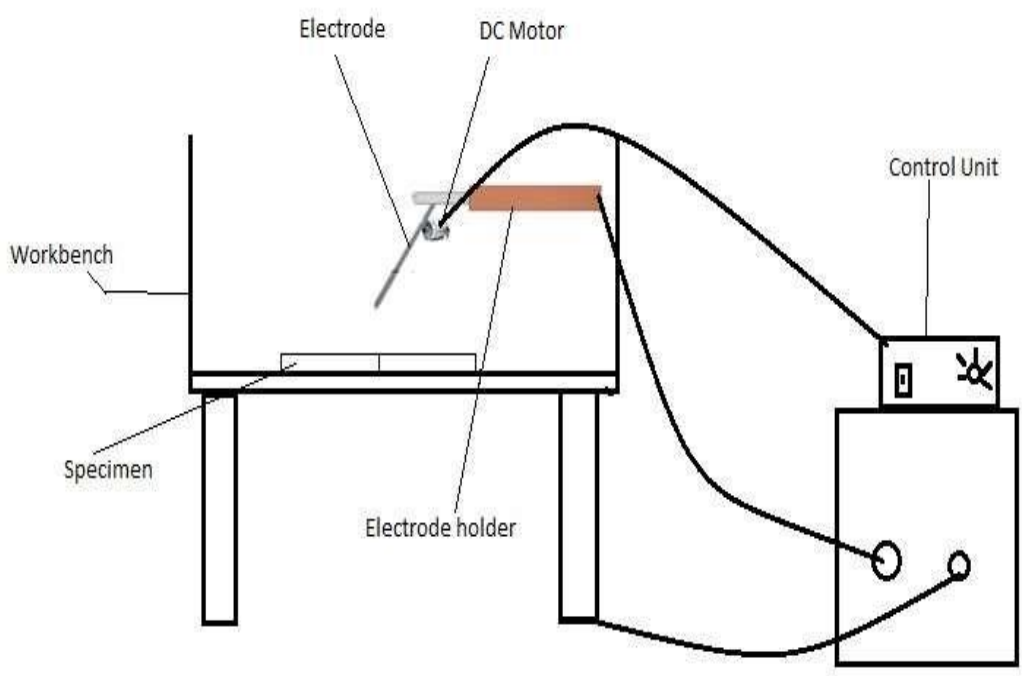

Figure 1: Line diagram of Electrode vibration setup

\subsection{Input Vibration Parameters}

With vibrator measuring tester, various frequencies and variables which dependent on the frequency are identified. A range of frequencies are identified between the operating range and the values are tabulated below table 1.

Table 1: Frequencies and Dependent parameters

\begin{tabular}{|c|c|c|c|c|}
\hline Exp. No. & $\begin{array}{l}\text { Frequency } \\
(\mathrm{Hz})\end{array}$ & $\begin{array}{l}\text { Displacement } \\
\text { (m) }\end{array}$ & Velocity x10 ${ }^{-5}(\mathrm{~m} / \mathrm{s})$ & $\begin{array}{c}\text { Acceleration } \\
\left(\mathbf{m} / \mathbf{s}^{2}\right)\end{array}$ \\
\hline 1 & 1071 & 0.005431 & 5.0760 & 2.691892 \\
\hline 2 & 1625 & 0.006124 & 5.7951 & 3.182112 \\
\hline 3 & 2292 & 0.007187 & 6.1758 & 4.025392 \\
\hline 4 & 2469 & 0.009145 & 6.9795 & 4.12369 \\
\hline 5 & 2828 & 0.010356 & 8.3754 & 4.29895 \\
\hline 6 & 3452 & 0.010864 & 10.1943 & 4.376166 \\
\hline 7 & 4450 & 0.0112364 & 13.5783 & 4.487418 \\
\hline 8 & 5450 & 0.0118619 & 18.6210 & 4.680458 \\
\hline
\end{tabular}

The combination of parameters chosen between voltage, current and frequencies are tabulated in the table below 2 . These are the parameters which were chosen to work with.

Table 2: Frequency with respect to DC motor volatage

\begin{tabular}{|c|c|c|}
\hline Exp. No. & $\begin{array}{c}\text { DC Motor } \\
\text { Voltage(V) }\end{array}$ & Frequency(Hz) \\
\hline 1 & 12.80 & 1071 \\
\hline 2 & 12.94 & 1625 \\
\hline 3 & 13.08 & 2292 \\
\hline 4 & 13.69 & 2469 \\
\hline 5 & 13.97 & 2828 \\
\hline 6 & 15.24 & 3452 \\
\hline 7 & 16.19 & 4450 \\
\hline 8 & 17.24 & 5450 \\
\hline
\end{tabular}




\section{Experimental Analysis of Weldments}

\subsection{Flexural Test}

Flexural strength of the material is called as rupture modulus, strength of bend or strength of fracture for materials which are brittle is defined as ability of material to resisting bending under the application of load. The bending strength of material is also known as the maximum stress undergone inside the material during rupture. Line diagram of specimen for Flexural strength and specimens before testing is shown in figure 2 and figure 3 .
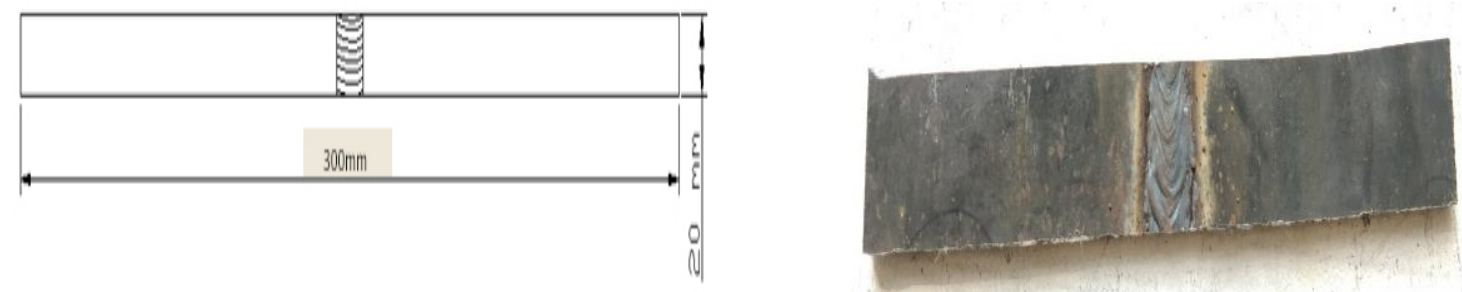

Figure 2: Line diagram of Specimen for Flexural strength. Figure 3: Specimen before testing

The process for performing the test generally involves a special connection on UTM machine. The penetration details of the test affect the results. Above figure is taken from ASTMD790 standards.

\section{RESULTS AND DISCUSSIONS}

The flexural test involves a bending at three points, which provides different values for elastic modulus during bending(E), flexural bending strain and flexural bending stress-strain reaction of material. This type of bending method also have some demerits such as results obtained by the testing process are very sensitive to work piece, geometry and rate of strain.

For conducting the test process, it involves a verified fixture on UTM. Test preparation details and conditioning which will affect the results of test. The following equations is used for calculating flexural strength.

$\sigma_{f}=\frac{3 P L}{2 b d^{2}}$ For a rectangular cross section.

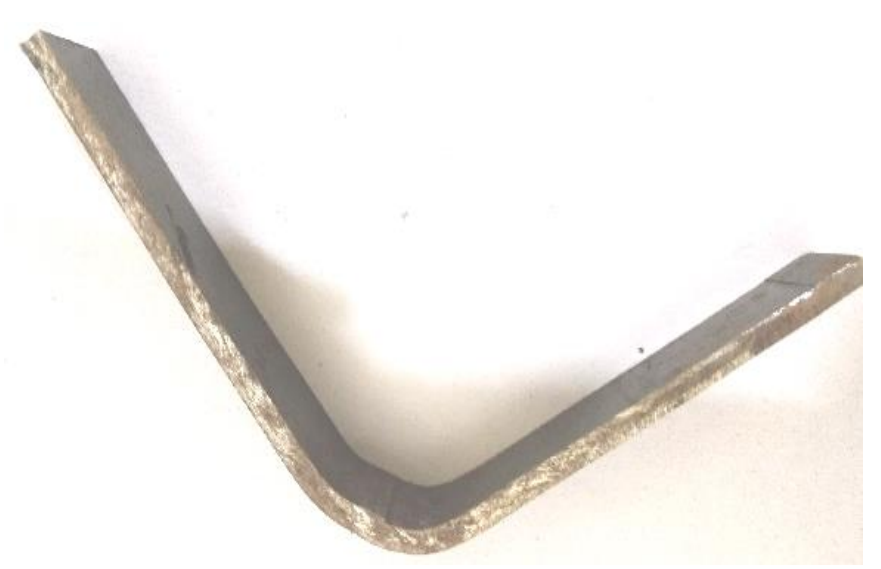

Figure 4: Specimen after testing

\subsection{Test Data}

UTM is used for conducting Flexural test to measure the flexural strength of the vibratory welded specimens. For Welding of Specimens different frequencies are chosen and it is compared with conventional welded specimens. The specimen starts to bend and after some time even though if load is increased there will be no effect on the specimen. The peak load along 
with elongation is obtained from the data produced during test. The load is used for calculating flexural strength, the specimen after testing is shown in figure 4. The experimental data is tabulated in the table 3.

Table 3: Test Results for Flexural Test

\begin{tabular}{|c|c|c|c|c|}
\hline $\begin{array}{c}\text { Specimen } \\
\text { No: }\end{array}$ & Frequency(Hz) & Load(KN) & Elongation(mm) & $\begin{array}{c}\text { Flexural } \\
\text { Strength(N/mm2) }\end{array}$ \\
\hline 1 & 0 & 442.2 & 12.4 & 398 \\
\hline 2 & 1071 & 471.1 & 13.8 & 424 \\
\hline 3 & 1625 & 480 & 11.5 & 432 \\
\hline 4 & 2292 & 491.1 & 20.9 & 442 \\
\hline 5 & 2469 & 501.1 & 15.4 & 451 \\
\hline 6 & 2828 & 527.7 & 11.4 & 475 \\
\hline 7 & 3452 & 552.2 & 13.4 & 497 \\
\hline 8 & 4450 & 566.6 & 12.2 & 510 \\
\hline 9 & 5450 & 473.3 & 22.4 & 426 \\
\hline
\end{tabular}

The obtained bending strength of weldments is compared with the weldments prepared without any vibrations. The results of the flexural strength with varying frequencies are represented in the below figure5. It is identified that enhanced flexural strength is obtained for the weldments which are prepared with the supplyment of the excitations. The enhancement is continued up to $4450 \mathrm{~Hz}$ frequency and from there the strength is droping due to increased arc gap with increased excitations. With this it is identified that increasing frequency will give improved results upto some extent, and from there onwards decreasing of properties will takes place due to arc gap.

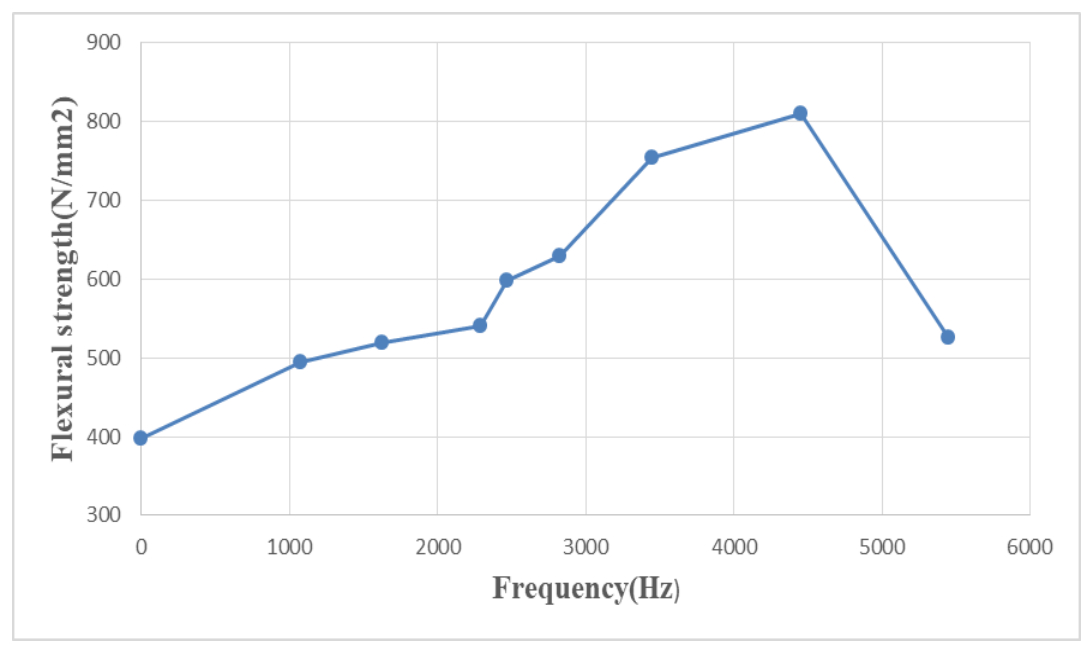

Figure 5: Variation of Flexural Strength with Frequency

In the figure 6 the load along with the variation in the flexural strength is shown. The flexural strength is increased at a frequency of $4450 \mathrm{~Hz}$ and dropped at a frequency of $5450 \mathrm{~Hz}$ because of increased arc gap. 
Load Vs Fluxural strength Comparision with respect to Frequency

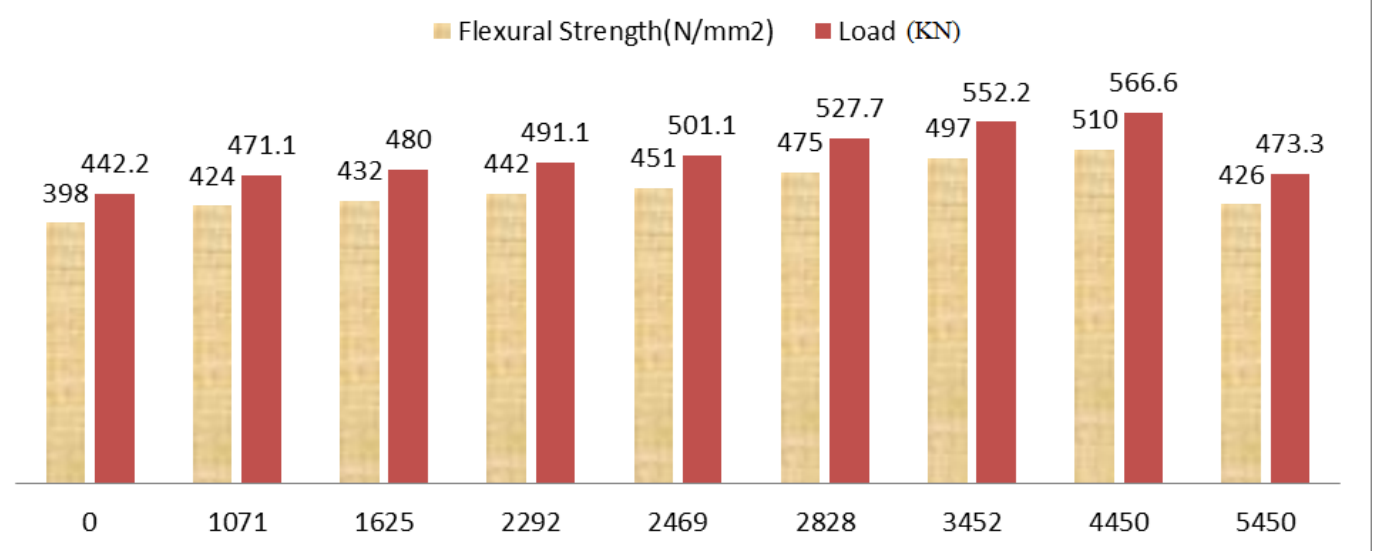

Figure 6: Load Vs Flexural strength Comparison with respect to frequency

\subsection{Microstructure of Weldments}

By observing the microstructure of the weldments at fusion zone which is shown in figure 6 , it is identified that without the application of vibrations the size of the dendrites formation is large. When it is compared to the microstructure of fusion with the application of vibrations at $4450 \mathrm{~Hz}$ the dendrites are breaks down into small size during the molten state and small nuclei formation is takes place after solidification. This results the fine grain refinement of the fusion zone before solidification leads to improved flexural strength.

\section{Microstructural Analysis of Welded Specimens}

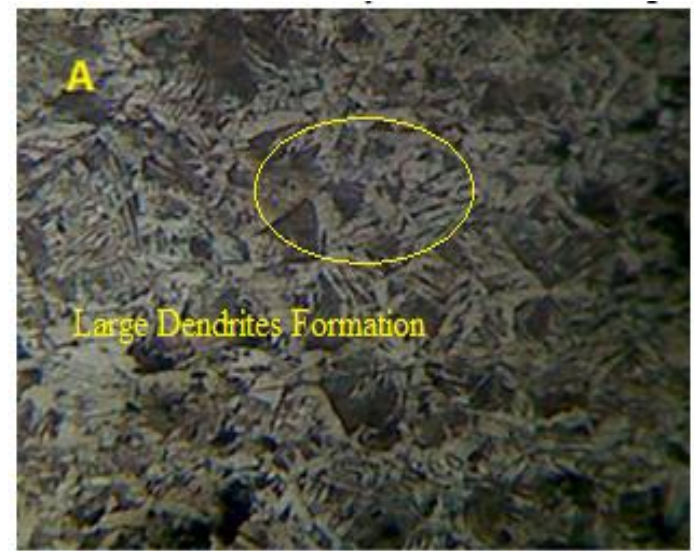

(A)Microstructure of weldment at $\mathrm{OHz}$

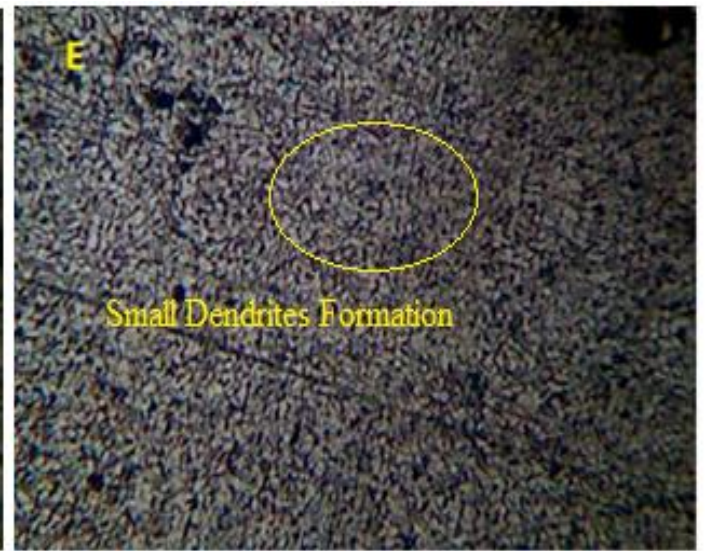

(B) Microstructure of weldment at $4450 \mathrm{~Hz}$

Figure 6: At Different frequencies Microstructure

\section{CONCLUSIONS}

The excitation frequencies had a great impact on the Flexural or bending Strength of weldments which were welded with electrode vibration welding. There is a significant increase in the Flexural strength of the work pieces welded with electrode vibration that of the work pieces welded without any vibrations. The specimens welded without excitations are found to have low values of Flexural strength when compared to those welded with the assistance of electrode vibrations. The increase in Flexural Strength is $28.14 \%$ (maximum) at $4450 \mathrm{~Hz}$ in comparison to that of without vibrations. By observing the microstructure the enhancement in flexural strength is due to the formation of large number of smaller nuclei resulting in 
finer grain structures.

\section{REFERENCES}

1. Shigeru Aoki, Tadashi Nishimura, Tetsumaro Hiroi, Seiji Hirai, "Reduction method for residual stress of welded joint using harmonic vibrational load". ScienceDirect received 23 January 2006; accepted 7 June 2006.

2. J. Kalpana, P.S. Rao, P.G. Rao, "Influence of amplitude on tensile strength of welded joints fabricated under vibratory weld conditioning”. Journal of mechanical engineering research and developments. ISSN: 1024-1752. Vol.39, No.3, 2016.

3. Musin, C.A. Walker, "Reduction method for residual stress of welded joint using random vibration", Nuclear Engineering and Design 235 (2005) 1441-1445.

4. Alaa Raad Hussein, Nawal Aswan Abdul Jail and Abd Rahim Abu Talib, "Improvement of mechanical welding properties by using induced harmonic vibration". Journal of applied sciences ISSn 1812-5654.

5. P. Govinda Rao, Dr. C L V R S V Prasad, Dr. D. Sreeramulu, Dr.V. Chitti Babu, M.Vykunta Rao, "Determination Of Residual Stresses Of Welded Joints Prepared Under The Influence Of Mechanical Vibrations By Hole Drilling Method And Compared By Finite Element Analysis", International Journal of Mechanical Engineering and Technology (IJMET), Volume 4, Issue 2, March - April (2013), pp 542-553.

6. Tso-Liang Teng and Peng-Hsiang Chang, "Effect of Welding Sequences on stress", Recived 26 March 2002 Accept to Novmber 2002 .

7. Dean Deng and ShoichiKiyoshima, "FEM prediction of welding residual stresses in a SUS304 girth-welded pipe with emphasis on stress distribution near weld start/end location”, Computational Materials Science 50 (2010) 612-621.

8. Sun, M., Sun, Y. and Wang, R. (2004). "Vibratory stress relieving of welded sheet steels of low alloy high strength steel". Materials Letters, 58(7-8), pp.1396-1399.

9. Weglowska, A., and Pietras, A. (2012). "Influence of the welding parameters on the structure and mechanical properties of vibration welded joints of dissimilar grades of nylons". Archives of Civil and Mechanical Engineering, 12(2), pp. 198-204.

10. Rao, D., Wang, D., Chen, L. and Ni, C. (2007). "The effectiveness evaluation of $314 L$ stainless steel vibratory stress relief by dynamic stress". International Journal of Fatigue, 29(1), pp.192-196.

11. Zhu, Q., Chen, L., Rao, D., Lu, L., and Xu, L. (2005). "Experimental study on electro-slag weld of blast furnace steel using vibratory conditioning technology". Hanjie Xuebao/Transactions of the China Welding Institution, 26 (2), pp. 56-58.

12. Bade, V. S. (2020). Experimental investigation on influence of electrode vibrations on hardness and microstructure of 1018 mild steel weldments. World Journal of Engineering.

13. T. Balarami Reddy , "Mechanical Performance of Green Coconut Fiber/HDPEComposites by Using Flexural Strength", International Journal of MechanicalEngineering (IJME), Vol. 3, Issue 1, pp. 53-66

14. Oyetunji O. R\& Hammed B. M, "The Effect of Overall Density on the Mechanical Properties of Flexible Polyurethane Foam", BEST: Journal of Management, Information Technology and Engineering (BEST: JMITE), Vol. 2, Issue 1, pp. 19-32

15. Remya Raju, Mathews M Paul \& K. A. Aboobacker, "Strength Performance of Concrete Using Bottom Ash as Fine Aggregate", IMPACT: International Journal of Research in Engineering \& Technology (IMPACT: IJRET), Vol. 2, Issue 9, pp. 111-122

16. Boorla Tharun \& Sreenu Ramavath, “Influence of Transverse Hole on Flexural Strength of RC Beam”, International Journal of Civil Engineering (IJCE), Vol. 8, Issue 1,pp. 1-12 

